\title{
Identification of differentially expressed proteins of Arthrospira (Spirulina) plantensis-YZ under salt-stress conditions by proteomics and qRT-PCR analysis
}

Huili Wang ${ }^{1 *}$, Yanmei Yang ${ }^{1}$, Wei Chen ${ }^{1}$, Li Ding ${ }^{1,2}$, Peizhen Li ${ }^{1}$, Xiaokai Zhao ${ }^{1}$, Xuedong Wang ${ }^{2}$, Aiying Li ${ }^{3}$ and Qiyu Bao ${ }^{1 *}$

\begin{abstract}
Arthrospira (Spirulina) platensis as a representative species of cyanobacteria has been recognized and used worldwide as a source of protein in the food, which possesses some unusual and valuable physiological characteristics, such as alkali and salt tolerance. Based on complete genome sequencing of Arthrospira (Spirulina) plantensis-YZ, we compared the protein expression profiles of this organism under different salt-stress conditions (i.e. $0.02 \mathrm{M}, 0.5 \mathrm{M}$ and $1.0 \mathrm{M} \mathrm{NaCl}$, respectively), using 2-D electrophoresis and peptide mass fingerprinting, and retrieved 141 proteins showing significantly differential expression in response to salt-stress. Of the 141 proteins, 114 Arthrospira (Spirulina) plantensis-YZ proteins were found with significant homology to those found in Arthrospira (76 proteins in Arthrospira platensis str. Paraca and 38 in Arthrospira maxima CS-328). The remaining 27 proteins belong to other bacteria. Subsequently, we determined the transcriptional level of 29 genes in vivo in response to $\mathrm{NaCl}$ treatments and verified them by qRT-PCR. We found that 12 genes keep consistency at both transcription and protein levels, and transcription of all of them but one were up-regulated. We classified the 141 differentially expressed proteins into 18 types of function categories using COG database, and linked them to their respective KEGG metabolism pathways. These proteins are involved in 31 metabolism pathways, such as photosynthesis, glucose metabolism, cysteine and methionine metabolism, lysine synthesis, fatty acid metabolism, glutathione metabolism. Additionally, the SRPs, heat shock protein and ABC transporter proteins were identified, which probably render Arthrospira (Spirulina) plantensis's resistance against high salt stress.
\end{abstract}

Keywords: Spirulina plantensis, Arthrospira, Metabolism pathway, Up-regulation, Salt-stress

\section{Introduction}

Cyanobacteria is a phylum of bacteria which obtains energy through photosynthesis, which can be classified into several subgroups by morphology (unicellular or filamentous) or function (N2-fixing and non-N2-fixing) [1]. Arthrospira (Spirulina) platensis (ASP) is one of representative species of cyanobacteria, and has been harvested or cultured as a source of protein in the food [2-4]. Scientists found that this organism possesses some unusual and

\footnotetext{
* Correspondence: whuili@163.com; baoqy@genomics.org.cn ${ }^{1}$ Institute of Biomedical Informatics/Zhejiang Provincial Key Laboratory of Medical Genetics, School of Life Sciences, Wenzhou Medical College, Wenzhou 325035, China

Full list of author information is available at the end of the article
}

valuable physiological characteristics, such as alkali- and salt-tolerance. Especially, it can grow at salt concentrations of $\sim 1.5$-fold higher than in sea water [5,6], making it often dominates in lakes with high alkalinity.

At present, salt stress is becoming a serious environmental issue because $7 \%$ of the land, $20 \%$ of the arable land and $50 \%$ of irrigated land in the world are salinized. The agricultural production was reported to be dramatically reduced in approximate $33 \%$ by soil salinization [7]. Therefore, mechanism elucidation of salt-tolerance in plants would allow us to grow salt-tolerant plants using biological engineering techniques.

With the rapid development in molecular biology techniques, the salt-tolerance mechanism of cyanobacteria has 
been gradually clarified. The optimal $\mathrm{Na}^{+}$concentration is 150-200 mM for the growth of cyanobacteria, and the cyanobacterium Aphanothece halophytica can grow well at a concentration of as high as $1000 \mathrm{mM} \mathrm{NaCl}$ [8]. It has been demonstrated that the sustained tolerance to high salt concentrations resulted from $\mathrm{Na}^{+} / \mathrm{H}^{+}$reverse collaborative transportation system, hydrated ion channels, synthesis of some lipid membrane composition and salt-stress induced proteins $[9,10]$.

For example, high salt-stress influences photosynthesis process of Synechococcus by inhibiting the expression of $p s b A$ gene encoded D1 protein, which is involved in the repair of PSII system [11]. Kanesaki and coworkers found that 28 genes specifically express in response to high salt-stress, 11 genes to high osmotic pressure, and 34 genes to both conditions in Synechocystis sp. PCC 6803 using the gene micro-array technology [12,13]. The expressed proteins in response to high osmotic pressure are mainly the metabolism-related lipoprotein A enzymes. However, they belong to hot shock proteins and glucosylglycerol-phosphate synthases. Moreover, some unknown proteins have been found to be highly expressed under adverse circumstance stress [14,15].

In the recent years, transcriptomics, proteomics and metabolomics technologies have been developed rapidly on the basis of cyanobacteria genomics studies under environmental stress conditions [16]. However, as for transcriptomic and proteomic analyses, the more advanced biological information technology is required to acquire the more reliable data [17]. The first commercial instrument for quantitative PCR (qPCR) created by American ABI Co., Ltd. in 1996 was thought to realize the detecting leap from traditional qualitative PCR to quantitative analysis. This technique can monitor slight changes of the whole biological system, and precisely quantify the gene expression level in the form of absolute or relative values. Consequently, high sensitivity, high accuracy, wide detection range and good repeatability led to wide application of quantitative PCR in quantitative gene expression study $[18,19]$.

The present paper aims to analyze the protein expression of ASP-YZ using 2-dimensional gel electrophoresis (2-DE) and MALDI-TOF/MS to reveal the responses of ASP-YZ to salt-stress at molecular level. This study would allow us understanding the environmental adaptability of cyanobacteria, and provide basic clues to further clarify the mechanism of adverse circumstance-resistance in ASP.

\section{Material and methods}

\section{Culture conditions and sample preparation}

ASP-YZ supplied by Chinese Academy of Agricultural Sciences (Beijing, China) was cultured in $0.02 \mathrm{M} \mathrm{NaCl}$ Zarrouk medium at $30^{\circ} \mathrm{C}$, light intensity of $8 \mathrm{klx}$ and
$75 \%$ humidity [20]. At logarithmic growth period, ASPYZ cells were transferred into fresh Zarrouk medium supplemented with $\mathrm{NaCl}$ at three different salt concentrations $(0.02,0.5$ and $1.0 \mathrm{M}$ representing control, medium and high salt concentrations, respectively) and cultivated for $7 \mathrm{~d}$. ASP-YZ growth curves are shown in Additional file 1: Figure S1. The harvested cells were rinsed three times with phosphate-based buffer, and then centrifuged at 9,000 rpm for $5 \mathrm{~min}$ to remove old and dead cells which were deposited at the tube bottom. The suspended cells were rinsed five times with ultra-pure water to remove $\mathrm{NaCl}$ completely. The cells for protein extraction were stored at $-80^{\circ} \mathrm{C}$ for further analysis.

\section{Protein extraction}

The harvested cells prepared as above were put in liquid nitrogen for 10-15 $\mathrm{min}$, followed by grinding to fine powder. Soluble proteins were extracted by adding $1.5 \mathrm{~mL}$ of extraction buffer (10\% trichloroacetic acid and $0.1 \%$ dithiothreitol (DTT) in acetone) to $100 \mathrm{mg}$ lyophilized fine powder, followed by $1 \mathrm{~min}$ of Vortex agitation. The homogenate was kept at $-20^{\circ} \mathrm{C}$ for $2-3 \mathrm{~h}$, and then centrifuged at $35,000 \mathrm{~g}, 4^{\circ} \mathrm{C}$ for $15 \mathrm{~min}$. The precipitates were resuspended with acetone containing $0.1 \%$ DTT and kept at $-20^{\circ} \mathrm{C}$ overnight. After centrifugation, the precipitates were resuspended with acetone containing $0.1 \%$ DTT at $-20^{\circ} \mathrm{C}$ for $1-2 \mathrm{~h}$, then centrifuged at $35,000 \mathrm{~g}, 4^{\circ} \mathrm{C}$ for $15 \mathrm{~min}$, and vacuum dried. After the resultant powder was resuspended in lysis buffer (8 M Urea, 4\% NP-40, 0.8\%Bio-lyte (pH 3.0-10.0), 40 mM Tris base (pH 8.5), 10 mM DTT, 1 mM PMSF (phenylmethyl sulfonylfluoride), $2 \mathrm{mM}$ EDTA- $\mathrm{Na}_{2}$, the suspension was ultrasonically treated for $12 \mathrm{~min}$ in ice. The insoluble precipitates were removed by centrifugation at 35,000 $\mathrm{g}$ for $30 \mathrm{~min}$ at $4^{\circ} \mathrm{C}$, and the protein concentration of the final supernatant was measured according to Bradford protein assay [21].

\section{Two-dimensional gel electrophoresis}

For one-DE, the protein extract $(22 \mu \mathrm{L})$ was diluted to a final concentration of $1000 \mu \mathrm{g} / \mathrm{ml}$ with an IEF rehydration solution, consisting of $17.5 \mu \mathrm{L}$ DTT, $1.75 \mu \mathrm{L}$ IPG (immobilized $\mathrm{pH}$ gradient buffer solution) and $309 \mu \mathrm{L}$ R-Buffer (2 M sulfourea, $7 \mathrm{M}$ urea, 4\% CHAPS, $40 \mathrm{mM}$ Tris, $2 \mathrm{mM}$ TBP reductant and $0.2 \%$ Biolyte). Then, the above diluted protein extract $(350 \mu \mathrm{L})$ was subjected to Immobiline DryStrips ( $\mathrm{pH}, 4-7$; Length, $17 \mathrm{~cm}$; Amersham Bioscience), as shown in Additional file 1: Figure S2. Each experiment group contained three biological replicates, generating 9 individual samples. For the firstdimensional IEF (isoelectric focusing) based on $\mathrm{pI}$ value of each protein, the procedures were as follows: $50 \mathrm{~V}$ for 4-6 h, $500 \mathrm{~V}$ for $1 \mathrm{~h}, 1,000 \mathrm{~V}$ for $1 \mathrm{~h}, 8,000 \mathrm{~V}$ for $1 \mathrm{~h}$, $8,000 \mathrm{~V}$ for $80,000 \mathrm{Vh}$ and finally $500 \mathrm{~V}$ for $20 \mathrm{~h}$. After 
this, strips were firstly equilibrated for $12 \mathrm{~min}$ in reducing solution (6 M urea, $50 \mathrm{mM}$ Tris- $\mathrm{HCl} \mathrm{pH} 6.8$, $30 \% \mathrm{v} / \mathrm{v}$ glycerol, $2 \% \mathrm{w} / \mathrm{v}$ SDS and $2.5 \% \mathrm{w} / \mathrm{v}$ DTT). The strips were subsequently placed for another $15 \mathrm{~min}$ in alkylating equilibration buffer containing $2.5 \% \quad(\mathrm{w} / \mathrm{v})$ iodoacetamide instead of $2 \%$ iodoacetamide. Second dimension SDS-PAGE was run on homogeneous $12 \% \mathrm{~T}$, 2.6\% C (piperazine diacrylamide) polyacrylamide gels cast in glass plates. Electrophoresis was carried out at $20^{\circ} \mathrm{C}$, and $1.0 \mathrm{~W} / \mathrm{Gel}$ for $30 \mathrm{~min}$ and kept at $15 \mathrm{~W} / \mathrm{Gel}$ until the dye front reached the bottom of the gel using Ettan-Dalt six unit. Gels were fixed overnight in 50\% ethanol/5\% acetic acid, and rinsed (5 gels/tray) four times ( $1 \mathrm{~h}$ each time) in $1,800 \mathrm{~mL}$ of deionized water. Following the washing, the gels were equilibrated in $1.9 \mathrm{~g} / \mathrm{L}_{\mathrm{AgNO}_{3}}(1 \mathrm{~L} /$ tray $)$ for 60 to $90 \mathrm{~min}$. An additional 1-h wash in $\mathrm{Na}_{2} \mathrm{CO}_{3}(7.5 \mathrm{~g} / \mathrm{L})$ following the reducing step [22]. The protein spots were scanned by UNAX Powerlook 2100XL (Bio-Rad) and analyzed by ImageMaster 2D platinum 5.0 (Amersham Bioscience) according to manufacturer's instructions.

\section{Image acquisition and data analysis}

Images were properly cropped and optimized before performing the inter-gel matching of the standard protein maps. Before spot matching, the internal standard image gel with greatest number of spots was used as a master gel. The spot detection parameters were optimized by checking different protein spots in certain regions of the gel, which were then automatically detected, followed by visual inspection for removal or addition of undetected spots. Spot detection was refined by a manual spot edition where needed. The spots that were present on at least two gels of one treatment or control based on the image analysis were identified as expressed protein spots. The abundance of each protein spot was estimated by the percentage volume (Vol\%), that is, the spot volumes were normalized as a percentage of the total volume in all the spots present in the gel to correct the variability because of loading, gel staining and destaining $[23,24]$. The percentage volumes were used to designate the significant differentially expressed spots (at least three-fold increase/decrease and statistically significant as calculated by Student's $t$-test, at $P<0.05)$. Triplicate gels were used for each sample. Only those with reproducible and significant changes were considered to be differentially expressed protein spots.

\section{Mass spectrometry analysis and database search}

Differentially expressed protein spots were manually selected and excised, then de-stained in 50\% $\mathrm{ACN}$ in $25 \mathrm{mmol} / \mathrm{L} \mathrm{NH}_{4} \mathrm{HCO}_{3}$ at $37^{\circ} \mathrm{C}$ for $30 \mathrm{~min}$. Next, $50 \mu \mathrm{L}$ ultra-pure $\mathrm{H}_{2} \mathrm{O}$ and $50 \mu \mathrm{L} 50 \% \mathrm{ACN}$ were added, followed by $100 \mu \mathrm{L}$ of $100 \% \mathrm{ACN}$. The gels were rehydrated in a $5 \mu \mathrm{L}$ of a trypsin (Promega, Madison, USA) solution $\left(20 \mu \mathrm{g} / \mathrm{ml}\right.$ in $\left.25 \mathrm{mmol} / \mathrm{L} \mathrm{NH}_{4} \mathrm{HCO}_{3}\right)$ for $30 \mathrm{~min}$. Next, $20 \mu \mathrm{L}$ cover solution $(25 \mathrm{mmol} / \mathrm{L}$ $\mathrm{NH}_{4} \mathrm{HCO}_{3}$ ) was added, and digestion took place overnight at $37^{\circ} \mathrm{C}$. The supernatants were transferred into another tube, and the gels were extracted once with $50 \mu \mathrm{L}$ extraction buffer (67\% ACN and 5\% TFA). The peptide extracts and the supernatant of the gel spot were combined and then completely dried. Samples were re-suspended in $5 \mu \mathrm{L} 0.1 \%$ TFA followed by mixing in $1: 1$ ratio with a matrix consisting of a saturated solution of $\mathrm{CHCA}$ in 50\% ACN containing $0.1 \%$ TFA. The 1:1 mixture was spotted on a stainless steel sample target plate. The peptide samples were analyzed with a MALDI-TOF/TOF Proteomics Analyzer (Bruker Daltonics, Bremen, Germany). A combined search (MS plus MS/MS) was performed using Bruker Daltonics BioTools 3.0 software (Bruker Daltonics Inc). The TOF spectra were recorded in positive ion reflector mode with a mass range from 800 to $4000 \mathrm{Da}$. About eight subspectra with 60 shots per subspectrum were accumulated to generate one main TOF spectrum.

Data were searched on the Internet using a Mascot search engine (Matrix Science Ltd., London, UK) against all entries in the NCBInr database, which contained accessible public protein sequences (http://www.ncbi.nlm. nih.gov/nuccore/NZ_ACSK01001820.1/ Arthrospira platensis str. Paraca NZ_ACSK01001820) and (http://www. ncbi.nlm.nih.gov/nuccore/NZ_ABYK00000000.1/ Arthrospira maxima CS-328), and the unpublished Arthrospira platensis database. The unpublished database was built by our group after nearly complete sequencing and annotation of ASP-YZ. All peptide masses were assumed monoisotopic and $[\mathrm{M}+\mathrm{H}]^{+}$. The other parameters used for search were as follows: taxonomy, other bacteria; enzyme, trypsin; the fixed modification; carbamidomethyl (C); the variable modification, Glu->pyro-Glu (N-term Q) and oxidation $(\mathrm{M})$; mass toll $= \pm 100 \mathrm{pm}$. The confidence in the peptide mass fingerprinting matches $(P<0.05)$ was based on the MOWSE Score and confirmed by the accurate overlapping of the matched peptides with the major peaks of the mass spectrum. Only the significant hits, as defined by a MASCOT probability analysis $(P<0.05)$, were accepted. These differential proteins were grouped in their respective metabolic pathways using COG software online (ftp://ftp.ncbi.nih.gov/pub/COG, E-value < 0.0001).

\section{qRT-PCR analysis of the differentially expressed genes}

The primer sets, shown in Additional file 1: Table S1, were designed for amplification of $16 \mathrm{~S}$ rRNA and differentially expressed genes using Premier 5.0 software, and synthesized by Shanghai Sonny Biological Technology Co., Ltd. (Shanghai, China).

To validate the differential proteins of ASP-YZ at transcriptional level in vivo, qRT-PCR was performed using 
A

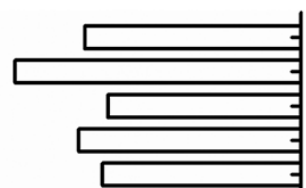

Posttranslational modification (ORF1976)

Cell motility and secretion (ORF3769)

Coenzyme metabolism (ORF4488)

Signal transduction mechanisms (ORF2861)

Cell envelope biogenesis (ORF4043)

Energy production and conversion (ORF2740)

Energy production and conversion (ORF2739)

Function unknown (ORF2313)

Function unknown (ORF4004)

Function unknown (ORF4030)

Function unknown (ORF2155)

Function unknown (ORF1456)

Function unknown (ORF4634)

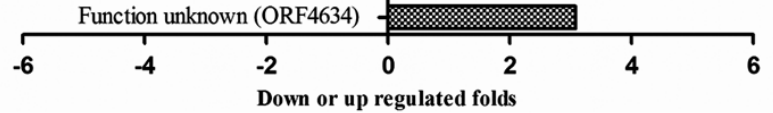

B

Spots present in $0.02 \mathrm{M} \mathrm{NaCl}$ group Spots present in $0.5 \mathrm{M} \mathrm{NaCl}$ group

\section{$\dot{\Delta}$}

Posttranslational modification (ORF1746)

Posttranslational modification (ORF 1368)

Cell division (ORF0639)

Inorganicion transport and metabolism (ORF 1911)

Nucl eotide transport and metabolism (ORF3877)

Nucl cotide transport and metabolism (Spot243)

Translation, ribosomal structure(ORF5117)

Translation, ribosomal structure(Spot657)

Translation, ribosomal structure(ORF 3535)

Function unknown (ORF0273)

Function unknown (Spot240)

Function unknown (ORF4635)

Function unknown (ORF2155)

General function prediction (Spot317)

General function prediction (ORF 3860)

Energy production and conversion (ORF2754)

Energy production and conversion (ORF3397)

Amino acid transport and metabolism (ORF3910)

Carbohydrate transport and metabolism (ORF3807)

Carbohydrate transport and metabolism (ORF3807)

Carbohydrate transport and metabolism (ORF1396)

Cell envelope biogenesis(ORF5367)

Cell envelope biogenesis(ORF0323)

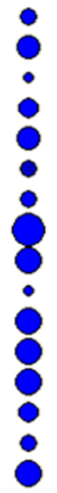

(ORF3402) Cell envelope biogenesis

(ORF3277) General function prediction only

(ORF3807) Carbohydrate transport and metabolism

(ORF2281) Posttranslational modification

(ORF2155) Function unknown

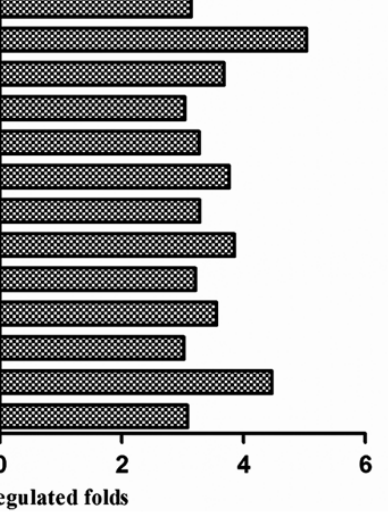

Function unknown (Spot 184)

Function unknown (ORF0361)

Function unknown (ORF 2155)

Function unknown (ORF4633)

Function unknown (ORF5516)

Cell envelope biogenesis (ORF 1751)

General function prediction (ORF1251)

Posttranslational modification (ORF1368)

Posttranslational modification (ORF 1434)

Translation, ribosomal structure(ORF5117)

Translation, ribosomal structure(ORF4662)

Translation, ribosomal structure(ORF1074)

Carbohydrate transport and metabolism (ORF4691)

Signal transduction mechanisms (ORF1869)

Figure 1 (See legend on next page.) 
(See figure on previous page.)

Figure 1 The differential protein points between medium salt $(0.5 \mathrm{M} \mathrm{NaCl})$ treatment and the $\mathrm{control}(0.02 \mathrm{M} \mathrm{NaCl})$. ( $\mathrm{Note}$ ( $\mathrm{A})$ The differential protein points with $>3.0$-fold changes in medium salt $(0.5 \mathrm{M} \mathrm{NaCl})$ treatment compared with the control $(0.02 \mathrm{M} \mathrm{NaCl})$. (B) The proteinspots of absent or present difference between the two groups (the relative abundance (Vol\%) of "present" protein calculated by the ratio of volume of each protein spot to volume of total protein spots in the whole gel,ranging from 0.928\% to 8.06\% as shown in Additional file 1: Table S3-B).

the StepOne ${ }^{\text {тм }}$ RT-PCR System (Applied Biosystem, USA). Total RNAs were extracted from ASP-YZ cultured in the control and medium salt concentrations using RNeasy Plant Mini Kit (Qiagen, Germany) according to manufacturer instructions and treated with Dnase I by RNase-Free Dnase Set (Qiagen, Germany). cDNA was obtained by reverse transcription using PrimeScript RT-PCR Kit (TaKaRa, Japan), following the procedures composed of an initial denaturation time of $5 \mathrm{~min}$ at $95^{\circ} \mathrm{C}, 35$ cycles of amplification comprising of a denaturation step for $1 \mathrm{~min}$ at $95^{\circ} \mathrm{C}$, and the annealing and extension temperatures as listed in Additional file 1: Table S2. Relative quantification of the targets in each sample was carried out using the signal of $16 \mathrm{~S}$ rRNA as a control.

The copy numbers in two samples were normalized, and the differentially expressed levels were then calculated using the following equation:

$$
\text { Folds }=\frac{G_{t} \times C_{h}}{C_{t} \times G_{h}}
$$

where $G_{t}, G_{h}, C_{t}$ and $C_{h}$ represent target genes of the treatments, housekeeping genes of the treatments, target genes of the controls and housekeeping genes of the controls, respectively.

\section{Results}

\section{2-DE profiles of total ASP-YZ proteins in response to} different salt concentrations

The expressed protein profiles of ASP-YZ under three salt concentrations of $0.02 \mathrm{M}$ (control), $0.5 \mathrm{M}$ and $1.0 \mathrm{M}$ were analyzed by 2-DE (with triplicate gels each salt concentration, see Additional file 1: Figure S2), followed by the statistical evaluation of the protein spots using ImageMaster 2D platinum 5.0 software for isoelectric point, molecular weight, relative expression abundance and protein-spot matching information etc. The overall protein numbers of ASP-YZ cultured in different salt concentrations appeared similar. Identical protein spots in the paired gels between different salt concentrations were also analyzed using the lower salt concentrations gels as the reference in each pair. There were 583 protein spots matched between the control $(0.02 \mathrm{M} \mathrm{NaCl})$ and $0.5 \mathrm{M} \mathrm{NaCl}$ gels (with correlation coefficient of 0.937 and matching rate of $83.90 \%$ ), 467 between the control and $1.0 \mathrm{M} \mathrm{NaCl}$ gels (with correlation coefficient of 0.948 and matching rate of $72.68 \%$ ) and 532 between
$0.5 \mathrm{M} \mathrm{NaCl}$ and $1.0 \mathrm{M} \mathrm{NaCl}$ gels (with correlation coefficient of 0.964 and matching rate of $78.69 \%$ ). Eighteen protein spots and their fold changes were found at the medium salt concentration $(0.5 \mathrm{M})$, which is over 3 -fold higher differential expression compared to the control $(0.02 \mathrm{M})$ (Figure $1 \mathrm{~A})$. In addition, 23 proteins were solely present under the medium salt treatment, while 16 proteins were solely present under the control (Figure 1B). There were 14 protein spots which are over 3-fold higher differential expression at the high $\mathrm{NaCl}$ concentration $(1.0 \mathrm{M})$ compared to the control (Figure 2A). In addition, 7 proteins were solely present under the high salt treatment, while 30 proteins were solely present under the control (Figure 2B).

By comparing the differential protein expression in the medium and high salt concentrations, 8 protein spots were found to express differentially by $>3$-fold higher at $0.5 \mathrm{M} \mathrm{NaCl}$ concentration than at $1.0 \mathrm{M}$ concentration (Figure 3A). In addition, 6 protein spots were solely present under the medium salt treatment, while 19 protein spots were solely present under the high salt treatment (Figure 3B). In total, 141 differentially expressed protein spots were obtained from the control $(0.02 \mathrm{M})$, medium $(0.5 \mathrm{M})$ and high $(1.0 \mathrm{M})$ salt-stress conditions (see Additional file 1: Table S3 A-F).

\section{PMF of the differential protein-spots and results of MALDI-TOF/MS analysis}

In order to get more information on differential proteins, 141 differential spots were identified using MALDI-TOF/MS analysis. By MASCOT searching, these positive protein spots could be attributed to 82 classes, among which 76 proteins exhibit high homology with those in Arthrospira platensis strain Paraca, 38 proteins in Arthrospira maxima CS-328 and the remaining 27 proteins belong to bacteria.

By comparing the theoretical and actual values of PI and isoelectric point acquired by MS and Gel Map Analytical Software, we performed COG function prediction and classified these 132 positive proteins into 18 functional categories (Figure 4). The detailed information on 141 differentially expressed proteins is summarized in Additional file 1: Table S3 (A-F) and Table S4 (A-F).

\section{qRT-PCR analysis of the differentially expressed genes Selection of differentially expressed genes}

We selected the typical 29 genes for further validation, which are possible salt-tolerant genes predicted by 
(See figure on previous page.)

Figure 2 The differential protein points between high salt $(1.0 \mathrm{M} \mathrm{NaCl})$ treatment and control $(0.02 \mathrm{M} \mathrm{NaCl})$. (Note: (A) The differential protein points with $>3.0$-fold changes in high salt (1.0 M NaCl) treatment group compared to control $(0.02 \mathrm{M} \mathrm{NaCl})$. (B) The protein-spots of absent or present difference between the two groups (the relative abundance (Vol\%) of "present" protein calculated by the ratio of volume of each protein spot to volume of total protein spots in the whole gel,ranging from 1.208\% to 11.872\%, as shown in Additional file 1: Table S3-D).

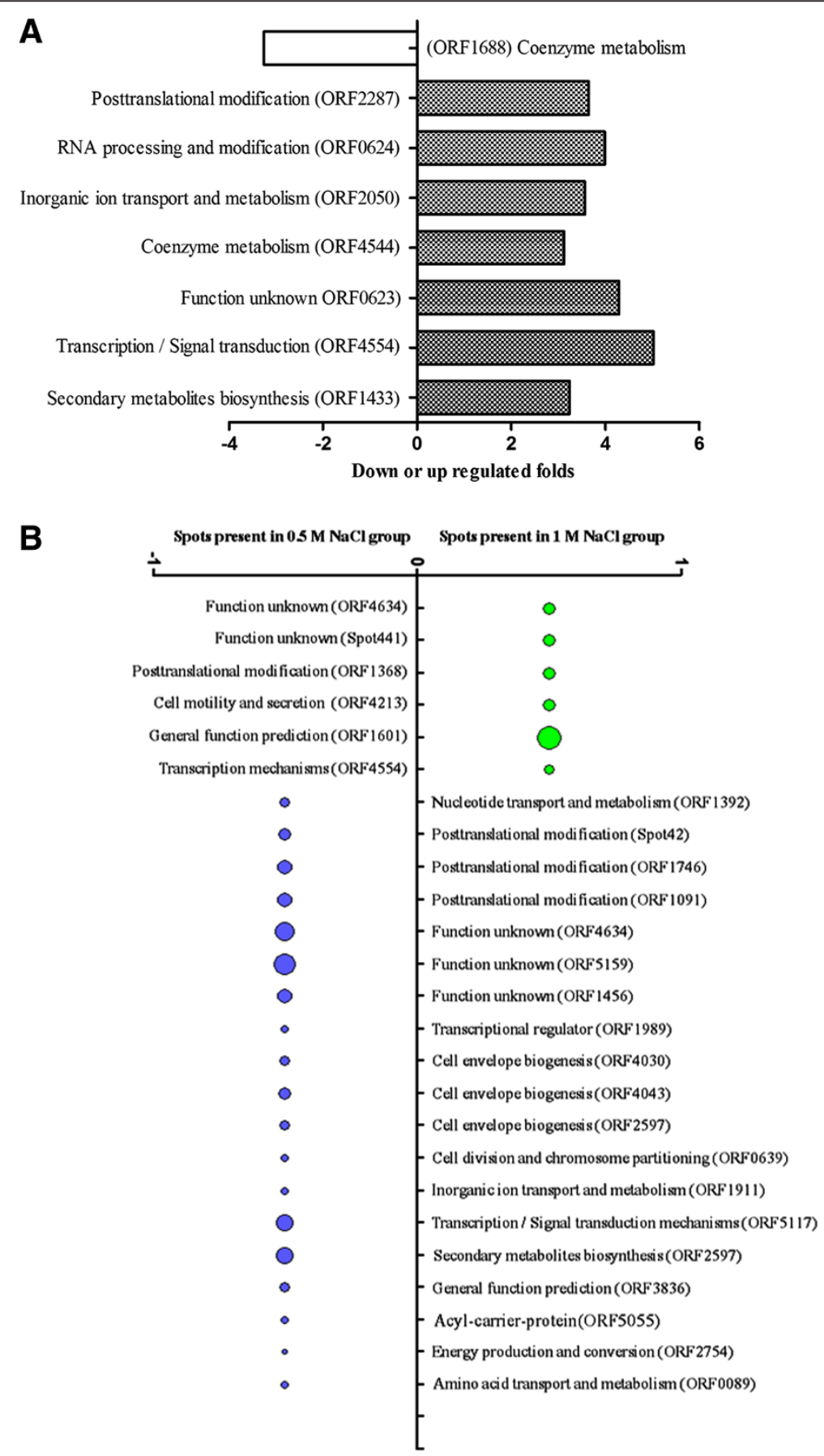

Figure 3 The differential protein points between high salt $(1.0 \mathrm{M} \mathrm{NaCl})$ treatment and medium salt $(0.5 \mathrm{M} \mathrm{NaCl})$ treatment. (Note: (A) The differential protein points with >3.0-fold changes in high salt $(1.0 \mathrm{M} \mathrm{NaCl})$ treatment compared to medium salt $(0.5 \mathrm{M}$ NaCl) treatment. (B) The protein-spots of absent or present difference between the two groups (the relative abundance (Vol\%) of "present" protein calculated by the ratio of volume of each protein spot to volume of total protein spots in the whole gel, ranging from $2.170 \%$ to $22.854 \%$, as shown in Additional file 1: Table S3-F). 


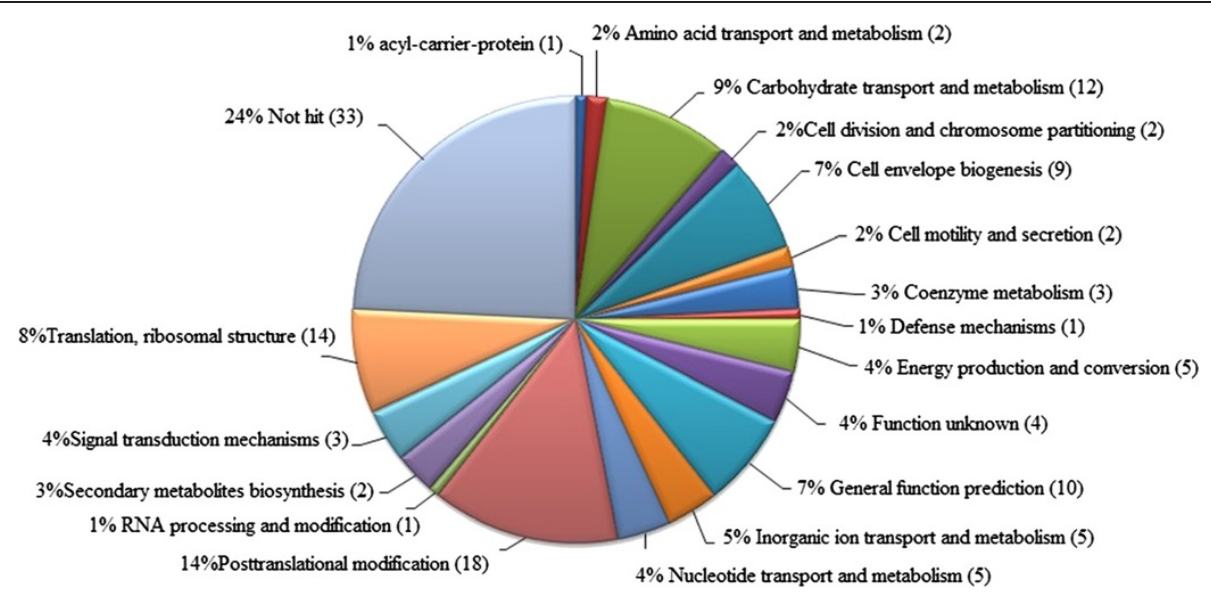

Figure 4 COG functional classification of 132 positive differential expression proteins.

previous studies [25-31], and the present results by metabolic pathway positioning through KEGG analysis, whose functions were involved in photosynthesis, glycolytic pathway, oxidative phosphorylation, amino acid and fatty acid synthetic metabolic pathway. Table 1 summarizes the information, annotation and metabolic pathway of 29 genes.

\section{The purity and concentration of total RNA}

Through agarose gel electrophoresis, the extracted RNA in both control and medium salt treatment showed a good integrity and a high purity, and had no degradation (see Additional file 1: Figure S3). The $\mathrm{OD}_{260} / \mathrm{OD}_{280}$ values were 2.09 and 2.03 , and the RNA concentrations were 441.2 and $113.6 \mathrm{ng} / \mu \mathrm{L}$, respectively, in the control $(0.02 \mathrm{M})$ and medium salt $(0.5 \mathrm{M})$ treatment.

\section{Standard curve of $q R T-P C R$}

For the 29 salt-tolerant genes, the qRT-PCR technique was used to further confirm consistency between their transcriptional level and gene expression. All of the melting curves showed a single peak, suggesting a good specificity (see Additional file 1: Figure S4). The non-detectable fluorescence signal in the negative control indicates that the reaction system was not polluted during the analysis. As shown in Additional file 1: Table S5 and Table S6, the calibration curves, regression coefficients and amplification efficiencies of 16S rRNA (control) and target genes indicate efficient amplification with high specificity.

\section{The relative transcription level of the genes using $q R T-P C R$}

The relative mRNA transcription level of the positive proteins detected by qRT-PCR for the control and medium salt group is shown in Figure 5. Under saltstress conditions, the transcription of 28 genes was upregulated, while only one gene transcription level was down-regulated. Of the 28 up-regulated genes, the genes with 2 to 3-fold transcription level were ORF4632, ORF4633, ORF4634, ORF3807 and ORF1688. Additionally, the genes up-regulated the transcription level to a higher extent included ORF2739 and ORF4030 ( $>3$-fold), ORF4138 and ORF4213 (>4-fold), ORF1433, ORF1198 and ORF3277 (5-10 times), ORF4535, ORF2050, ORF2740, ORF2281, ORF5055 and ORF2155 (>10-fold), and ORF2287, ORF1989, ORF4103, ORF273, ORF5516, ORF1251, ORF3023, ORF624, ORF3910 and ORF4635 (>100-fold), respectively.

More interestingly, the fold change of ORF1989, ORF4103, ORF273, ORF5516, ORF1251, ORF3023, ORF624 and ORF4635 with up-regulated transcription level reached up to more than 10,000-fold. Of the $29 \mathrm{tar}-$ get genes, the transcription of only ORF1911 gene was down-regulated by ca. 5 -fold.

Of the 29 target genes, the protein expression of 17 genes was consistent with gene transcription, representing $58.62 \%$ of the total target genes. The genes, with transcription levels of > 3-fold, were ORF4030, ORF3910, ORF4935, ORF2740, ORF2739, ORF1433, ORF2287, ORF2050, ORF4213, ORF4635, ORF273, ORF1189 and ORF624, respectively. The remaining 12 genes showed inconsistent protein expression with transcription level, which is $41.38 \%$ of the total target genes. The comparison of transcription and protein expression of the target genes is summarized in Table 2.

Finally, we performed the metabolic pathway positioning through KEGG analysis, and found 13 genes with $>3$-fold up-regulated protein under medium saltstress (Figure 1A). The 13 genes were involved in photosynthesis, glycolytic pathway, oxidative phosphorylation, amino acid and fatty acid synthetic metabolic pathway. Additionally, ORF4213 and ORF2287 function in signal recognition particle (SRP) subunit and molecular chaperone DnaK (Hsp70). Moreover, the 7 genes with unknown function were found. 
Table 1 Annotation and proposed metabolic pathways of the differential protein spots obtained from the MS-searching

\begin{tabular}{|c|c|c|c|c|c|c|c|c|c|c|c|}
\hline Spot & Spot & ORF & Accession no. & Gene product (best hit in NCBInr database) & $\begin{array}{l}\text { MW (Da) } \\
(T / E)\end{array}$ & $\mathrm{PI}(\mathrm{T} / \mathrm{E})$ & $\begin{array}{l}\text { Matched } \\
\text { peptides }\end{array}$ & Cov & $\begin{array}{l}\text { MASCT } \\
\text { Score }\end{array}$ & E-value & $\begin{array}{l}\text { Fold } \\
\text { change }\end{array}$ \\
\hline \multicolumn{12}{|c|}{ General function } \\
\hline CK701 & M718 & 3277 & ZP_03275759 & $\begin{array}{l}\text { FAD-dependent pyridine nucleotide disulphide } \\
\text { oxidoreductase [Arthrospira maxima CS-328] }\end{array}$ & $47147 / 42726$ & $6.67 / 6.49$ & 6 & $20 \%$ & 78 & 0.018 & -4.70 \\
\hline \multicolumn{12}{|c|}{ Posttranslational modification, protein turnover, chaperones } \\
\hline CK275 & M305 & 2281 & ZP_06380867 & $\begin{array}{l}\text { Peptidyl-prolyl cis-trans isomerase, cyclophilintype } \\
\text { [Arthrospira str. Paraca] }\end{array}$ & $23921 / 28931$ & $4.74 / 4.49$ & 6 & $36 \%$ & 75 & 0.036 & -3.65 \\
\hline M908 & H653 & 2287 & ZP_03274434 & Molecular chaperone DnaK [Arthrospira maxima CS-328] & $62452 / 57079$ & $4.70 / 5.57$ & 27 & $38 \%$ & 150 & 1.00E-09 & 3.65 \\
\hline \multicolumn{12}{|c|}{ Fructose and mannose metabolism } \\
\hline CK461 & $\mathrm{H}-\mathrm{N}$ & 4535 & ZP_06381408 & GDP-L-fucose synthase [Arthrospira str. Paraca] & $35652 / 35258$ & $5.59 / 6.14$ & 23 & $53 \%$ & 260 & $1.00 \mathrm{E}-20$ & / \\
\hline \multicolumn{12}{|c|}{ Fatty acid biosynthesis } \\
\hline CK361 & $\mathrm{H}-\mathrm{N}$ & 5055 & ZP_06383266 & Enoyl-(acyl carrier protein) reductase [Arthrospira str. Paraca] & $27751 / 31814$ & $5.57 / 5.83$ & 11 & $37 \%$ & 79 & 0.013 & / \\
\hline M344 & $\mathrm{H} 224$ & 1433 & YP_002521548 & $\begin{array}{l}\text { 3-oxoacyl-[acyl-carrier protein] reductase } \\
\text { [Thermomicrobium roseum DSM 5159] }\end{array}$ & $28631 / 31269$ & $6.54 / 5.34$ & 9 & $34 \%$ & 73 & 0.049 & 3.24 \\
\hline
\end{tabular}

Photosynthesis - antenna proteins

\begin{tabular}{|c|c|c|c|c|c|c|c|c|c|c|c|}
\hline CK47 & $\mathrm{H}-\mathrm{N}$ & 4103 & ZP_03271327 & Phycobilisome core component [Arthrospira maxima CS-328] & $17433 / 14807$ & $6.26 / 5.74$ & 14 & $84 \%$ & 165 & $3.30 \mathrm{E}-11$ & / \\
\hline CK342 & M394 & 2155 & ZP_06382427 & Phycobilisome linker polypeptide [Arthrospira str. Paraca] & $29450 / 31199$ & $9.25 / 5.68$ & 15 & $55 \%$ & 218 & $1.6 \mathrm{E}-16$ & -3.26 \\
\hline CK423 & $\mathrm{H}-\mathrm{N}$ & 4633 & ABV01983 & Cpch [Arthrospira Sp-16] & $30852 / 33929$ & $7.82 / 6.29$ & 25 & $60 \%$ & 295 & $3.30 \mathrm{E}-24$ & / \\
\hline CK467 & $\mathrm{H} 342$ & 4632 & ABB84420 & Cpci [Arthrospira Sp-5] & $32790 / 35621$ & $8.33 / 4.59$ & 19 & $53 \%$ & 150 & 1.00E-09 & 3.09 \\
\hline CK-N & $\mathrm{H} 69$ & 4634 & ZP_06380686 & Phycocyanin, alpha subunit [Arthrospira maxima CS-328] & $17703 / 19259$ & $5.82 / 5.89$ & 10 & $58 \%$ & 91 & 0.00076 & I \\
\hline CK-N & M252 & 4635 & ABD64607 & Phycocyanin beta chain [Arthrospira] & $18506 / 28381$ & $5.19 / 4.58$ & 11 & $55 \%$ & 98 & 0.00016 & / \\
\hline \multicolumn{12}{|c|}{ Purine metabolism } \\
\hline CK-N & M137 & 1911 & ZP_06383116 & Adenylylsulfate kinase [Arthrospira str. Paraca] & $19897 / 22320$ & $5.22 / 5.46$ & 16 & $79 \%$ & 200 & $1 e-14$ & / \\
\hline \multicolumn{12}{|c|}{ Lysine biosynthesis } \\
\hline CK-N & M463 & 3910 & ZP_06382240 & Dihydrodipicolinate synthase [Arthrospira str. Paraca] & $30869 / 34837$ & $5.20 / 5.80$ & 22 & $51 \%$ & 141 & $8.3 e-09$ & / \\
\hline CK500 & M548 & 4030 & ZP_03276569 & Diaminopimelate epimerase [Arthrospira maxima CS-328] & $32452 / 37662$ & $9.22 / 6.83$ & 39 & $76 \%$ & 310 & $1 e-25$ & 3.56 \\
\hline \multicolumn{12}{|c|}{ Glutathione metabolism } \\
\hline CK517 & $\mathrm{H} 384$ & 4938 & ZP_06381009 & Glutathione synthetase [Arthrospira str. Paraca] & $36159 / 38491$ & $5.93 / 6.64$ & 15 & $43 \%$ & 100 & 0.0001 & 4.04 \\
\hline \multicolumn{12}{|c|}{ Glycolysis/Gluconeogenesis } \\
\hline CK-N & M595 & 3807 & ZP_03274253 & $\begin{array}{l}\text { Glyceraldehyde-3-phosphate dehydrogenase, type I } \\
\text { [Arthrospira maxima CS-328] }\end{array}$ & $36534 / 39635$ & $6.07 / 5.26$ & 24 & $61 \%$ & 110 & 0.00001 & / \\
\hline \multicolumn{12}{|c|}{ Cysteine and methionine metabolism } \\
\hline M778 & $\mathrm{H} 545$ & 1688 & ZP_06381331 & Adenosylhomocysteinase [Arthrospira str. Paraca] & $46667 / 45550$ & $5.64 / 5.98$ & 25 & $52 \%$ & 245 & $3.3 e-19$ & 3.26 \\
\hline \multicolumn{12}{|c|}{ Oxidative phosphorylation } \\
\hline CK145 & M140 & 2740 & ZP_06381970 & F-type $\mathrm{H}^{+}$-transporting ATPase subunit delta [Arthrospira str. Paraca] & $20108 / 22132$ & $6.15 / 6.79$ & 15 & $53 \%$ & 116 & $2.6 \mathrm{e}-06$ & 3.77 \\
\hline CK109 & M93 & 2739 & ZP_03274295 & F-type $H^{+}$-transporting ATPase subunit $\beta[$ Arthrospira maxima CS-328] & 19538/17970 & $5.14 / 5.04$ & 13 & $59 \%$ & 114 & $4.2 \mathrm{e}-06$ & 3.28 \\
\hline
\end{tabular}


Table 1 Annotation and proposed metabolic pathways of the differential protein spots obtained from the MS-searching (Continued)

\begin{tabular}{|c|c|c|c|c|c|c|c|c|c|c|c|}
\hline \multicolumn{12}{|c|}{$\mathrm{ABC}$ transporters } \\
\hline M800 & H564 & 2050 & ZP_03275033 & $\begin{array}{l}\text { ABC-type nitrate/nitrite transport system substrate-binding protein } \\
\text { [Arthrospira maxima CS-328] }\end{array}$ & $48859 / 47107$ & $4.68 / 4.46$ & 26 & $50 \%$ & 235 & $3.30 \mathrm{E}-18$ & 3.57 \\
\hline \multicolumn{12}{|c|}{ Protein export } \\
\hline $\mathrm{M}-\mathrm{N}$ & $\mathrm{H} 185$ & 4213 & YP_798213 & $\begin{array}{l}\text { Signal recognition particle subunit SRP54[Leptospira borgpetersenii } \\
\text { serovarHardjobovis L550] }\end{array}$ & $49178 / 28565$ & $7.08 / 5.46$ & 8 & $24 \%$ & 74 & 0.046 & / \\
\hline \multicolumn{12}{|c|}{ Transcriptional regulator } \\
\hline M111 & $\mathrm{H}-\mathrm{N}$ & 1989 & & Transcriptional regulator, abrb family [Arthrospira maxima CS-328] & $15532 / 19479$ & $8.49 / 4.22$ & 11 & $44 \%$ & 90 & 0.0011 & / \\
\hline \multicolumn{12}{|c|}{ Function unknown } \\
\hline$\overline{C K 934}$ & $\mathrm{M}-\mathrm{N}$ & 1251 & ZP_06381540 & Hypothetical protein aplap_07632 [Arthrospira str. Paraca] & $67407 / 65336$ & $5.66 / 6.20$ & 19 & $42 \%$ & 166 & $2.6 \mathrm{E}-11$ & / \\
\hline CK424 & $\mathrm{M}-\mathrm{N}$ & 5516 & ZP_03272395 & Conserved hypothetical protein [Arthrospira maxima CS-328] & $41116 / 34016$ & $6.04 / 6.08$ & 13 & $50 \%$ & 205 & $3.3 \mathrm{E}-15$ & / \\
\hline CK283 & $\mathrm{M}-\mathrm{N}$ & 3023 & ZP_06383801 & Hypothetical protein AplaP_19221 [Arthrospira platensis str. Paraca] & $23973 / 29221$ & $7.03 / 6.22$ & 9 & $58 \%$ & 94 & 0.00044 & / \\
\hline CK202 & $\mathrm{H} 127$ & 1198 & ZP_06382670 & Hypothetical protein aplap_13413 [Arthrospira str. Paraca] & $29241 / 25864$ & $8.15 / 5.52$ & 11 & $54 \%$ & 103 & $5.2 \mathrm{e}-05$ & 4.70 \\
\hline CK-N & M175 & 273 & ZP_06384609 & Hypothetical protein aplap_23383 [Arthrospira str. Paraca] & $20229 / 25353$ & $5.93 / 5.71$ & 9 & $49 \%$ & 121 & $8.3 e-07$ & / \\
\hline M839 & H591 & 624 & ZP_06384828 & Hypothetical protein aplap_24525 [Arthrospira str. Paraca] & $37661 / 50381$ & $4.91 / 5.25$ & 27 & $61 \%$ & 226 & 2.60E-17 & 3.99 \\
\hline
\end{tabular}

Note: (1) $0.02 \mathrm{M} \mathrm{NaCl}$ for control group (CK): $0.5 \mathrm{M} \mathrm{NaCl}$ for medium salt treatment (M); and $1.0 \mathrm{M} \mathrm{NaCl}$ for high salt treatment (H).

(2) $\mathrm{CK}-\mathrm{N}, \mathrm{M}-\mathrm{N}$ and $\mathrm{H}-\mathrm{N}$ represent no protein-spots are observed in control, medium and high salt treatment groups, respectively.

(3) The grey mark indicates up-regulation of proteins.

(3) The grey mark indicates up-regulation of proteins.
(4) The native values in fold column indicate the down-regulation.

(5) $T / E$ indicates theoretical values/experimental values. 


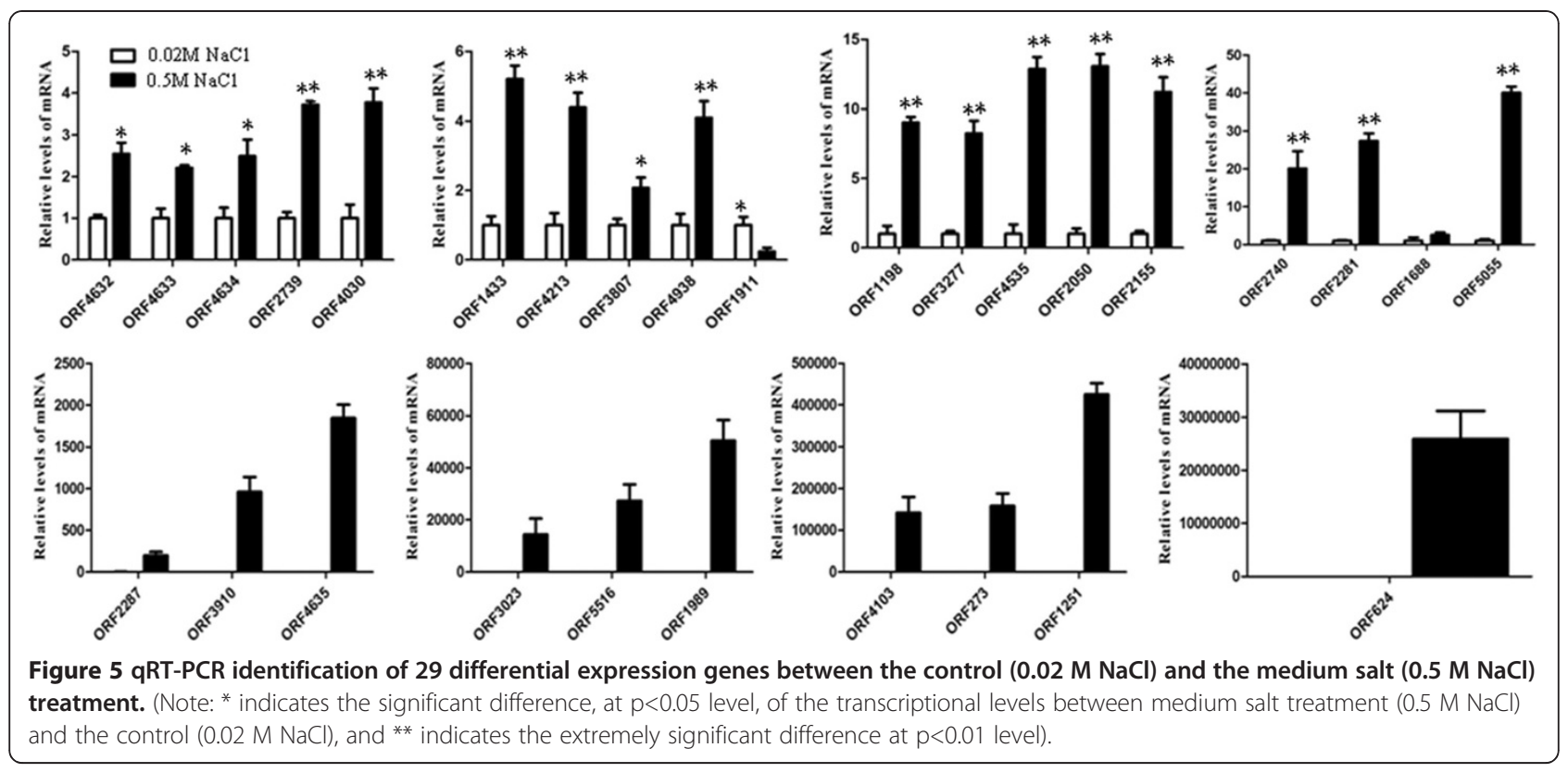

\section{Discussion}

Cyanobacteria's resistance to highly salty environments has been triggering great research interest to reveal the mechanism. Some findings suggested that osmotic stress as a main factor could result in decreasing of water content in cytoplasm and an increase in intracelluar salt concentration [32]. In the current study, we identified some up-regulated proteins in ASP-YZ at different salt concentrations by proteomics techniques, suggesting that up-regulation of the protein is a response to high salt environment. ASP-YZ acclimates to high salt environment probably through modulating osmotic regulation, because Glyceraldehyde-3-phosphate dehydrogenase (ORF3807, Table 1), the key enzyme of carbohydrate and amino acid metabolism, is detected. It has reported that generation of more trehalose is required to resist external osmotic pressure to protect the intracellular macromolecule stability [33]. We speculate that salt-stress might result in the signal recognition particle (SRP) to synthesize more glucose, fructose and betaine. The synthesis of these energy substances can maintain intracellular pressure by balancing the osmotic pressure caused by salt-stress.

Under salt-stress conditions, oxygen free radicals in ASP-YZ cells are expected to accumulate rapidly, and are harmful to cells if they are not removed timely [34]. We identified some up-regulated genes, at both protein and transcription levels, (Glutathione synthetase, ORF4938, Table 1) involved in glutathione synthetase in ASP-YZ, suggesting that salt-stress can enhance biosynthesis of intracellular glutathione, which in turn helps cells to clean oxygen free radicals, and to maintain the stability of intracellular environment [35].
The unsaturated fatty acid in thylakoid membrane of cyanobacteria has been found to play an important role in the process of adaptation to salt stress, by relieving the inhibition of synthesis and activity of $\mathrm{Na}^{+} / \mathrm{H}^{+}$transporter caused by salt-stress [36]. The up-regulation of 3-oxoacyl[acyl-carrier protein] reductase (ORF1433, Table 1), at both protein and transcription levels, might promote the photosynthesis under salt-stress conditions, which accelerates the active expulsion of $\mathrm{Na}^{+}$through $\mathrm{Na}^{+} / \mathrm{H}^{+}$transporter and thus decreases ion poisoning [37,38].

The transcription level of gene ORF4213 encoding signal recognition subunit SRP54 increased by $>4$-fold, which is in consistent with up-regulation of protein expression detected by 2 -DE. The intracellular protein orientation transfer is an important link among protein quantity control, protein recognition and protein transport system, which is mediated by SRP [39]. SRPs are RNA-protein complexes, which can identify existence of the signal peptide in the nascent polypeptide chain and thus can mediate the recognition and transport of the secretory and membrane proteins [40]. Therefore, cell physiological metabolism and lesion are associated with protein targeting transport. It is predictable that expression of some SRP proteins (SRP54, ORF4213, Table 1) in response to salt-stress results from acceleration of the intracellular nascent peptide synthesis and enhancement of identification and transporter activity of the secretory and membrane proteins [41].

Under salt-stress conditions, many cyanobacteria can induce the expression of salt-stress proteins, in proportional increase to the tolerance to salt [42]. The expression of stress proteins and molecular chaperone Dnak in ASP-YZ were also found to be up-regulated in the present study, 
Table 2 The comparison between qPCR and proteomic analyzing result

\begin{tabular}{|c|c|c|c|}
\hline ORF & Fold change from qPCR results & Fold change from proteomic results & Consistency \\
\hline 3277 & $U R>8$ & $\mathrm{DR}>4(0.5 \mathrm{M}$ and control) & No \\
\hline 2281 & UR $>27$ & $\mathrm{DR}>3(0.5 \mathrm{M}$ and control) & No \\
\hline 4535 & UR $>12$ & $\mathrm{DR}>3(1.0 \mathrm{M}$ and control) & No \\
\hline 5055 & $U R>40$ & $\mathrm{DR}>3(0.5 \mathrm{M}$ and $1.0 \mathrm{M}$ treatment $)$ & No \\
\hline 4103 & UR $>142017$ & $\mathrm{DR}>3(1.0 \mathrm{M}$ and control) & No \\
\hline 1911 & $\mathrm{DR}>4$ & $\mathrm{DR}>3(0.5 \mathrm{M}$ and control) & No \\
\hline 4633 & $U R>2$ & $\mathrm{DR}>3(0.5 \mathrm{M}$ and control) & No \\
\hline 2155 & UR $>11$ & $\mathrm{DR}>3(0.5 \mathrm{M}$ and control) & No \\
\hline 4030 & $U R>3$ & UR>3(0.5 $\mathrm{M}$ and control) & Yes \\
\hline 1989 & $U R>50406$ & $\mathrm{DR}<3(0.5 \mathrm{M}$ and $1.0 \mathrm{M}$ treatment $)$ & No \\
\hline 1251 & UR $>425003$ & $\mathrm{DR}<3(0.5 \mathrm{M}$ and control) & No \\
\hline 5516 & $U R>27288$ & $\mathrm{DR}<3(0.5 \mathrm{M}$ and control) & No \\
\hline 3023 & $U R>14294$ & $\mathrm{DR}<3(0.5 \mathrm{M}$ and control) & No \\
\hline 3910 & $U R>960$ & UR<3(0.5 $\mathrm{M}$ and control) & Yes \\
\hline 4938 & $U R>4$ & UR>4(1.0 M and control) & Yes \\
\hline 3807 & $U R>2$ & UR<3(0.5 $\mathrm{M}$ and control) & Yes \\
\hline 1688 & $U R>2$ & UR>3(0.5 $\mathrm{M}$ and $1.0 \mathrm{M}$ treatment $)$ & Yes \\
\hline 2740 & $U R>20$ & UR>3(0.5 $\mathrm{M}$ and control) & Yes \\
\hline 2739 & $U R>3$ & UR>3(0.5 $\mathrm{M}$ and control) & Yes \\
\hline 1433 & $U R>5$ & UR>3 (0.5 M and $1.0 \mathrm{M}$ treatment) & Yes \\
\hline 2287 & $U R>194$ & UR>3(0.5 $\mathrm{M}$ and $1.0 \mathrm{M}$ treatment $)$ & Yes \\
\hline 2050 & $U R>13$ & UR>3(0.5 $\mathrm{M}$ and $1.0 \mathrm{M}$ treatment $)$ & Yes \\
\hline 4213 & $U R>4$ & UR>3(0.5 $\mathrm{M}$ and $1.0 \mathrm{M}$ treatment $)$ & Yes \\
\hline 4632 & $U R>2$ & $\mathrm{UR}>3(1.0 \mathrm{M}$ and control) & Yes \\
\hline 4634 & $U R>2$ & UR>3(1.0 $\mathrm{M}$ and control) & Yes \\
\hline 4635 & UR $>1846$ & UR>3(0.5 M and control) & Yes \\
\hline 273 & UR $>158255$ & UR>3(0.5 $\mathrm{M}$ and control) & Yes \\
\hline 1198 & $U R>9$ & UR>4(1.0 M and control) & Yes \\
\hline 624 & UR $>25867164$ & UR>3(0.5 $\mathrm{M}$ and $1.0 \mathrm{M}$ treatment $)$ & Yes \\
\hline
\end{tabular}

making major contributions to promote the correct folding of intracellular protein and the tolerance to salt.

Under salt-stress, the up-regulated enzymes in ASP-YZ include peptidyl-prolylcis-trans isomerase, cyclophilin type (encoded by ORF2281), diaminopimelate epimerase (encoded by ORF4030), enoyl-[acyl-carrier protein] reductase (ORF5055), transcriptional regulator, abrB family (ORF1989) and FAD-dependent pyridine nucleotidedisulphide oxidoreductase (ORF3277). Of the above 5 genes, up-regulation of 4 genes (ORF-2281, -5055, -1989 and -3277) was observed at transcription level, while down-regulation of them at protein level. Obviously, the salt-tolerant mechanism of ASP-YZ is not solely mediated through up or down-regulation of genes, at transcription or translation level, in one metabolite or one metabolic pathway. It should be a perplexing result of the crossregulation of many physiological, biochemical and metabolic pathways.
It is worthy to note that each protein spot in gel does not necessarily accord to one kind of protein. The above phenomenon lies in: (1) the same gene has different expression products, (2) the same protein can form different spots due to different structural modification, and (3) the same protein can produce multiple protein fragments due to degradation. Overall, the above factors can lead to several protein spots attributed to the same protein (the same DNA Open Read Frame). Nevertheless, the protein spot changes in 2-DE images imply the change of protein (subunits), revealing that this kind of change (gene expression diversity and protein posttranslational modification) is unique advantage of 2-DE and proteomic techniques.

Some ASP-YZ genes, showing inconsistency between transcription and translation level, do not account for their independence on salt tolerance, and perhaps their major roles are regulatory effects including transcriptional 
regulation, differential processing of RNA transcript and differential translation of mRNA [43,44]. Regulation of gene transcription and translation could be controlled by activation and transformation of gene structure, initiation of transcription, post-transcriptional processing and transport, mRNA degradation, translation and posttranslational processing and protein degradation. The degradation of mRNA transcripts is an important reason to cause the inconsistency. Some inducible gene transcripts could be degraded immediately after translation and even in the course of translation [45]. The inconsistency between transcriptional and translational levels is influenced by many factors, and thus the further verification is required to elucidate its mechanisms.

Additionally, we detected that seven genes with unassigned functions was up-regulated, at transcription level, to a remarkably high extent, for instance, upregulated by 9 -fold for ORF1198, $1 \times 10^{4}$-fold ORF3023, $2 \times 10^{4}$-fold for ORF5516, $15 \times 10^{4}$-fold for ORF273, $42 \times 10^{4}$-fold for ORF1251, and $2586 \times 10^{4}$ for ORF624 genes, respectively. It is of great importance to predict the role of these unknown candidate genes induced by salt-stress. The expression of some genes with unknown function was found to be down-regulated obviously, including ORF3277, ORF2281, ORF5055, ORF1251, ORF5516 and ORF3023. Therefore, it is necessary to study extensively the expression regulation mechanism of these genes at the transcriptional level under saltstress conditions.

In a conclusion, we identified some interesting genes in response to salt-stress by proteomic analysis. To elucidate the salt-tolerant mechanism in ASP-YZ, the data in the present study will promote us to investigate further the expression regulation of these target genes.

\section{Additional file}

Additional file 1: Table S1. The primers used for amplification of target and $16 \mathrm{~S}$ rRNA genes. Table S2. Annealing and extension temperature for amplification of the target and 16S rRNA genes.

Table S3. (A) The ImageMaster 2D analytical results of differential protein spots (>3-fold) in the gels between $0.5 \mathrm{M} \mathrm{NaCl}$ treatment and control (0.02 M). (B) The ImageMaster 2D analytical results of the sole present protein spots in the gels of $0.5 \mathrm{M} \mathrm{NaCl}$ treatment or control $(0.02 \mathrm{M})$. (C) The ImageMaster 2D analytical results of differential protein spots ( $>3$-fold) in the gels between $1.0 \mathrm{M} \mathrm{NaCl}$ treatment and control (0.02 M). (D) The ImageMaster 2D analytical results of the sole present protein spots in the gels of $1.0 \mathrm{M} \mathrm{NaCl}$ treatment or control $(0.02 \mathrm{M})$. (E) The ImageMaster 2D analytical results of differential protein spots ( $>3$-fold) in the gels between $0.5 \mathrm{M} \mathrm{NaCl}$ and $1.0 \mathrm{M}$ treatment. (F) The ImageMaster 2D analytical results of the sole present protein spots in the gels of $1.0 \mathrm{M} \mathrm{NaCl}$ or $0.5 \mathrm{M}$ treatment. Table S4. (A) The MALDI-TOF/MS analytical results of differential protein spots (>3-fold) between $0.5 \mathrm{M} \mathrm{NaCl}$ treatment and control $(0.02 \mathrm{M})$. (B) The MS analytical results of the sole present protein spots in $0.5 \mathrm{M} \mathrm{NaCl}$ treatment or control $(0.02 \mathrm{M})$. (C) The MS analytical results of differential protein spots (>3-fold) between $1.0 \mathrm{M} \mathrm{NaCl}$ treatment and control $(0.02 \mathrm{M})$. (D) The MS analytical results of the sole present protein spots in $1.0 \mathrm{M} \mathrm{NaCl}$ treatment or control $(0.02 \mathrm{M})$. (E) The MS analytical results of differential protein spots (>3-fold) between 1.0 M and $0.5 \mathrm{M} \mathrm{NaCl}$ treatment. (F) The MS analytical results of the sole present protein spots in $1.0 \mathrm{M} \mathrm{NaCl}$ or $0.5 \mathrm{M}$ treatment. Table S5. The standard curve equation, regression coefficient and amplified efficiency of the $16 \mathrm{~S}$ rRNA genes. Table S6. The standard curve, regression coefficient and amplified efficiency of the target genes. Figure S1. ASP growth curve in different salt concentrations. Figure S2. The differential protein profiles of 2-DE of ASP in control $(0.02 \mathrm{M})$, medium salt treatment $(0.5 \mathrm{M})$ and high salt treatment $(1.0 \mathrm{M})$ groups. Figure S3. The AGE profile of total RNA in control and medium salt treatment. (Note: Lane 1, control; Lane 2, medium salt treatment.). Figure S4. The standard and melting curve of $16 \mathrm{~S}$ rRNA and sample.

\section{Abbreviations}

ASP: Arthrospira (Spirulina) platensis; KEGG: Kyoto Encyclopedia of Genes and Genomes; COG: Cluster of Orthologous Groups of Proteins; SRP: Signal Recognition Particle; 2-DE: 2-Dimensional Gel Electrophoresis; PMSF: Phenylmethyl Sulfonylfluoride; DTT: Dithiothreitol; IPG: Immobilized pH Gradient Buffer Solution; IEF: Isoelectric Focusing; PMF: Peptide Mass Fingerprinting.

\section{Competing interests}

The authors declare that they have no competing interests.

\section{Authors' contributions}

LPZ, CW and ZXK carried out sample collection and protein extraction, WHL and YYM carried out 2-DE, image acquisition and data analysis. LAY and WXD helped in manuscript revision. BQY and DL conceived, designed and implemented this study. All authors read and approved the final manuscript.

\section{Acknowledgements}

This work is supported by the National Natural Science Foundation of China (31071115, 30571009, 31270548), Science and Technology Foundation of Zhejiang Province, China (2009C33040), Natural Science Foundation of Zhejiang Province (Z307471), Science and Technology Foundation of Wenzhou City, China (\$20090002) and Foundation of Science and Technology Innovation Team of Zhejiang Province, China (2010R50048).

\section{Author details}

${ }^{1}$ Institute of Biomedical Informatics/Zhejiang Provincial Key Laboratory of Medical Genetics, School of Life Sciences, Wenzhou Medical College, Wenzhou 325035, China. ${ }^{2}$ School of Environmental Science and Public Health, Wenzhou Medical College, Wenzhou 325035, China. ${ }^{3}$ College of Life Sciences, Central China Normal University, Wuhan 450002, China.

Received: 3 July 2012 Accepted: 23 December 2012 Published: 30 January 2013

\section{References}

1. Takatomo F, Rei N, Shinobu O: Genomic structure of an economically important cyanobacterium, Arthrospira (Spirulina) platensis NIES-39. DNA Res 2010, 17:85-103.

2. Pulz O, Gross W: Valuable products from biotechnology of microalgae. Appl Microbiol Biotechnol 2004, 65:635-648.

3. Joanna MB, llona $G$, Jadwiga P: Effects of microcystins-containing cyanobacteria from a temperate ecosystem on human lymphocytes culture and their potential for adverse human health effects. Harmful Algae 2011, 10:356-365.

4. Chamorro G, Salazar M, Favila L: Pharmacology and toxicology of Spirulina alga. Rev Invest Clin 1996, 48:389-399.

5. Estrada JE, Bermejo P, Villar AM: Antioxidant activity of different fractions of Spirulina platensis protean extract. Farmaco 2001, 56:497-500.

6. Chamorro G, Salazar M, Araújo KG: Update on the pharmacology of Spirulina (Arthrospira), an unconventional food. Arch Latinoam Nutr 2002, 52:232-240.

7. Gao W, Shao YC, Yang J, Gao XB: Study on filtration of suitable krilium in saline-alkali soil amendments. Chinese Agr Sci Bull 2011, 27:154-160. in Chinese.

8. Ayachi S, El Abed A, Dhifi W: Chlorophylls, proteins and fatty acids amounts of Arthrospira platensis growing under saline conditions. Pak J Biol Sci 2007, 10:2286-2291. 
9. Latifi A, Ruiz M, Zhang CC: Oxidative stress in cyanobacteria. FEMS Microbiol Rev 2009, 33:258-278.

10. Marin K, Stirnberg M, Eisenhut M: Osmotic stress in Synechocystis sp. PCC 6803: low tolerance towards nonionic osmotic stress results from lacking activation of glucosylglycerol accumulation. Microbio/ 2006, 152:2023-2030.

11. Ohnishi N, Murata N: Glycinebetaine counteracts the inhibitory effects of salt stress on the degradation and synthesis of the D1 protein during photoinhibition in Synechococcus sp. PCC 7942. Plant Physiol 2006, 141:758-765.

12. Kanesaki Y, Suzuki I, Allakhverdiev SI, Mikami K, Murata N: Salt stress and hyperosmotic stress regulate the expression of different sets of genes in Synechocystis sp. PCC 6803. Biochem Biophy Res Commun 2002, 290:339-348.

13. Allakhverdiev SI, Murata N: Salt stress inhibits photosystem II and I in cyanobacteria. Photosynth Res 2008, 98:529-539.

14. Giulietti A, Overbergh L, Valckx D, Decallonne B, Bouillon R, Mathieu C: An overview of real-time quantitative PCR: applications to quantify cytokine gene expression. Methods 2001, 25:386-401.

15. Ustin SA: Absolute quantification of mRNA using real-time reverse transcription polymerase chain reaction assays. J Mol Endocrinol 2000, 25:169-193.

16. Pia $L B$, Sungsoon $P$, Anastasios $M$ : Engineering a platform for photosynthetic isoprene production in cyanobacteria, using Synechocystis as the model organism. Metab Eng 2010, 12:70-79.

17. Ornella C, Berta DC, José AN: Proteomic analyses of the response of cyanobacteria to different stress conditions. FEBS Lett 2009, 583:1653-1808.

18. Kogovšek P, Gow L, Pompe-Novak M: Single-step RT-PCR for sensitive detection and discrimination of Potato virus Y isolates. Sci Hortic 2009, 149:1-11.

19. Adrover MF, Muñoz MJ, Baez MV: Characterization of specific cDNA background synthesis introduced by reverse transcription in RT-PCR assays. Biochim 2010, 92:1839-1846.

20. Richmond A, Becker EW: Handbook of microalgal mass culture: Microalgae of economic potential. Boca Raton, Florida, USA: CRC Press, Inc; 1986:199-244.

21. Bradford OF: Adaptation of the Bradford protein assay to membranebound proteins by solubilizing in glucopyranoside detergents. Anal Biochem 1987, 126:11-17.

22. Eugen JS, Lonnie DA, David WS: Insulin-induced rapid decrease of a major protein in fat cell plasma membranes. J Biol Chem 1984, 19:12112-12116.

23. Zhang YM, Zhao JM, Xiang Y, Bian XC, Zuo QM, Shen Q, Gai JY, Xing H: Proteomics study of changes in soybean lines resistant and sensitive to Phytophthora sojae. Proteome Sci 2011, 9:52-64.

24. Zhang L, Yu ZF, Jiang $L$, Jiang J, Luo HB, Fu LR: Effect of post-harvest heat treatment on proteome change of peach fruit during ripening. J Proteomics 2011, 74:1135-1145.

25. Fulda S, Huang F, Nilsson F, Hagemann M, Norling B: Proteomics of Synechocystis sp. strain PCC 6803: Identification of periplasmic proteins in cells grown at low and high salt concentrations. Eur J Biochem 2000, 267:5900-5907.

26. Liska AJ, Shevchenko A, Pick U, Katz A: Enhanced photosynthesis and redox energy production contribute to salinity tolerance in Dunaliella, as revealed by homology-based proteomics. Plant Physiol 2004, 136:2806-2817.

27. Sudhir PR, Pogoryelov D, Kovacs L, Garab G, Kovacs L, Murthy SD: The effects of salt stress on photosynthetic electron transport and thylakoid membrane proteins in the cyanobacterium Spirulina platensis. Biochem Mol Biol 2005, 38:481-485.

28. Huang F, Fulda S, Hagemann M, Norling B: Proteomic screening of salt stress induced changes in plasma membranes of Synechocystis sp. strain PCC 6803. Proteomics 2006, 6:910-920.

29. Katz A, Waridel P, Shevchenko A, Pick U: Salt-induced changes in the plasma membrane proteome of the halotolerant alga Dunaliella salina as revealed by blue-native gel electrophoresis and nanoLC-MS/MS analysis. Mol Cell Proteomics 2007, 6:1459-1472.

30. Pandhal J, Snijders AP, Wright PC, Biggs CA: A cross-species quantitative proteomic study of salt adaptation in a halotolerant environmental isolate using $15 \mathrm{~N}$ metabolic labelling. Proteomics 2008, 8:2266-2284

31. Pandhal J, OW SY, Phillip CW, Catherine AB: Comparative proteomics study of salt tolerance between a nonsequenced extremely halotolerant cyanobacterium and its mildly halotolerant relative using in vivo metabolic labeling and in vitro isobaric labeling. J Proteome Res 2009, 8:818-828.
32. Gong HM, Tang LY, Wang J: Characterization of photosystem II in saltstressed cyanobacterial Spirulina platensis cells. Biochim Biophys Acta 2008, 1777:488-495.

33. Ravi K, Subhasha S, Akhilesh PS, Arvind MK, Sureshwar PS: Identification of maltooligo-syltrehalose synthase and maltooligosyltrehalose trehalohydrolase enzymes catalysing trehalose biosynthesis in Anabaena 7120 exposed to $\mathrm{NaCl}$ stress. J Plant Physiol 2005, 162:1030-1037.

34. Liu GJ, Hou CW, Lee SY: Antioxidant effects and UVB protective activity of Spirulina (Arthrospira) platensis products fermented with lactic acid bacteria. Process Biochem 2011, 46:1405-1410.

35. Liang GB, Du GC, Chen J: Salt-induced osmotic stress for glutathione overproduction in Candida utilis. Enzyme Microb Tech 2009, 45:324-329.

36. Victor G, Hugo S, Maria M: Changes in fatty acid profile and antioxidant systems in a Nostoc muscorum strain exposed to the herbicide bentazon. Process Biochem 2011, 46:2152-2162.

37. Mahajan S, Tuteja N: Cold, sality and drought stresses: an overview. Arch Biochem Biophys 2005, 444:139-158.

38. Gert JB, Martin MK, Tony F, Antoine RS: The NADH specific enoylacylcarrier protein reductase: characterization of a housekeeping gene involved in storage lipid synthesis in seeds of arabidopsis and other plant species. Plant Physiol Bioch 1998, 36:473-486.

39. Sowmya C, Justin C, Peera JA: Structure of the chloroplast signal recognition particle (SRP) receptor: domain arrangement modulates SRP-receptor interaction. J Mol Biol 2008, 375:425-436.

40. Asvin KKL, Camille M, Anne S: SRP keeps polypeptides translocationcompetent by slowing translation to match limiting ER-targeting sites. Cell 2008, 133:440-451.

41. Sandra JF, Stella AN, Susanne K, Andreas K: The mechanosensitive channel proteinMscL is targeted by the SRP to the novel YidC membranes insertion pathway of Escherichia Coli. J Mol Biol 2007, 356:995-1004.

42. Lan SB, Wu L, Zhang DL: Effects of drought and salt stresses on man-made cyanobacterial crusts. Eur J Soil Biol 2010, 46:381-386.

43. Matsuda N, Uozumi N: Ktr-mediated potassium transport, a major pathway for potassium uptake, is coupled to a proton gradient across the membrane in Synechocystis sp. PCC 6803. Biosci Biotech Biochem 2006, 70:273-275.

44. Kanesaki Y, Suzuki I, Allakhverdiev SI: Salt stress and hyperosmotic stress regulate the expression of different sets of genes in Synechocystis sp. PCC 6803. Biochem Biophy Res Commun 2002, 290:339-348.

45. Kurreck J: RNA interference: from basic research to therapeutic applications. Angew Chem Int Ed 2009, 48:1378-1398.

doi:10.1186/1477-5956-11-6

Cite this article as: Wang et al:: Identification of differentially expressed proteins of Arthrospira (Spirulina) plantensis-YZ under salt-stress conditions by proteomics and qRT-PCR analysis. Proteome Science 2013 11:6.

\section{Submit your next manuscript to BioMed Central and take full advantage of:}

- Convenient online submission

- Thorough peer review

- No space constraints or color figure charges

- Immediate publication on acceptance

- Inclusion in PubMed, CAS, Scopus and Google Scholar

- Research which is freely available for redistribution

Submit your manuscript at www.biomedcentral.com/submit
C) BioMed Central 